\title{
Overexpression of connexin 43 reduces melanoma proliferative and metastatic capacity
}

\author{
A Tittarelli ${ }^{1}$, I Guerrero ${ }^{1}$, F Tempio ${ }^{1,2}$, M A Gleisner ${ }^{1}$, I Avalos ${ }^{1}$, S Sabanegh ${ }^{1}$, C Ortíz ${ }^{1}$, L Michea ${ }^{1,2}$, \\ M N López ${ }^{1,2,3}$, A Mendoza-Naranjo ${ }^{4}$ and F Salazar-Onfray ${ }^{*, 1,2}$ \\ ${ }^{1}$ Institute of Biomedical Sciences, Faculty of Medicine, University of Chile, Santiago 8380453, Chile; ${ }^{2}$ Millennium Institute on \\ Immunology and Immunotherapy, Institute of Biomedical Sciences, University of Chile, Santiago 8380453, Chile; ${ }^{3}$ Research \\ Support Office, University of Chile Clinical Hospital, Santiago 8380453, Chile and ${ }^{4}$ UCL Cancer Institute, University College \\ London, 72 Huntley Street, London WC1E 6DD, UK
}

Background: Alterations in connexin 43 (Cx43) expression and/or gap junction (GJ)-mediated intercellular communication are implicated in cancer pathogenesis. Herein, we have investigated the role of $\mathrm{C} \times 43$ in melanoma cell proliferation and apoptosis sensitivity in vitro, as well as metastatic capability and tumour growth in vivo.

Methods: Connexin 43 expression levels, GJ coupling and proliferation rates were analysed in four different human melanoma cell lines. Furthermore, tumour growth and lung metastasis of high compared with low Cx43-expressing FMS cells were evaluated in vivo using a melanoma xenograft model.

Results: Specific inhibition of $\mathrm{C} \times 43$ channel activity accelerated melanoma cell proliferation, whereas overexpression of $\mathrm{C} \times 43$ increased GJ coupling and reduced cell growth. Moreover, Cx43 overexpression in FMS cells increased basal and tumour necrosis factor- $\alpha$-induced apoptosis and resulted in decreased melanoma tumour growth and lower number and size of metastatic foci in vivo.

Conclusions: Our findings reveal an important role for $\mathrm{C} \times 43$ in intrinsically controlling melanoma growth, death and metastasis, and emphasise the potential use of compounds that selectively enhance Cx43 expression on melanoma in the future chemotherapy and/or immunotherapy protocols.

Gap junction (GJ)-mediated intercellular communication (GJIC) is a fundamental mechanism for the maintenance of cellular homeostatic balance. Gap junctions are involved in the control of cell proliferation, differentiation, cell death and gene expression among other functions (Hervé and Derangeon, 2013; Carette et al, 2014). Each GJ channel is formed by two hexameric structures called connexons, each provided by one of the two neighbouring cells. A connexon is composed of six polytopic transmembrane protein subunits termed connexins $(\mathrm{Cx})$ that determine the permeability and regulatory properties of the GJ channel. The molecular cutoff of GJs is $\sim 1 \mathrm{kDa}$, allowing the exchange of small metabolites, ions, secondary messengers and small peptides between coupled cells (Harris, 2007). Over 21 different isoforms of Cxs have been characterised in humans (Meşe et al, 2007), with $\mathrm{Cx} 43$ being the most ubiquitously expressed connexin in mammals (Neijssen et al, 2007).

Connexin gene mutations and/or variations in their expression level or subcellular localisation patterns have been observed in a plethora of human diseases. All of them have, as a common factor, alterations in intercellular communication, apoptosis and proliferation (Laird, 2010; Pfenniger et al, 2011; Koulakoff et al, 2012). Decreased or diminished expression and/or function of Cxs have 
been observed in most tumour cell lines and in solid tissue tumours, including melanoma (Huang et al, 1999; Zhang et al, 2003; Haass et al, 2004; Naus and Laird, 2010). The role of GJs in tumour progression has been studied mainly through the ectopic reintroduction of $\mathrm{Cx}$ genes into tumour cell lines. Ectopic expression of $\mathrm{Cx} 43$ has been shown to reduce cell proliferation in many distinct cancer cells, including in mouse melanoma cell lines (Huang et al, 1998; Fukushima et al, 2007; Ableser et al, 2014). The mechanisms that may be involved in the inhibition of tumour cell growth by $\mathrm{Cx} 43$ re-expression include enhanced sensitivity to cell death, increased propagation of death signals and inhibition of proliferation via the regulation of specific kinases (Huang et al, 2002; Krutovskikh et al, 2002; Zhang et al, 2003). However, there is limited information about the role of $\mathrm{Cx} 43$ expression in cell proliferation/cell death and metastatic capacity in human melanoma. In this regard, Su et al (2000) observed that overexpression of $\mathrm{Cx} 43$ in a malignant melanoma cell line resulted in the suppression of the anchorage-independent growth, suggesting that $\mathrm{Cx} 43$ may also be a tumour suppressor gene in human melanoma. Recently, Zucker et al (2013) demonstrate that the overexpression of a dominant-negative Cx43 mutant decreases the anchorage-independent growth and increases the invasive potential of human melanoma cells.

In contrast with the established role of Cxs regulating growth of tumour cells in culture, the role of Cxs in tumour cell invasion and metastasis is controversial. Several reports suggest that Cxs might reduce tumour metastasis (Li et al, 2008; Sato et al, 2008; Bodenstine et al, 2010; Plante et al, 2011; Wang et al, 2013), whereas others argue the opposite effect (Naus and Laird, 2010; Stoletov et al, 2013), highlighting cell- and context-specific components of the process. In the present study, we aimed to evaluate the role of $\mathrm{Cx} 43$ expression in cell proliferation, apoptosis and metastatic capacity in human melanoma. Using a combination of in vitro and in vivo assays, we provide new insights into the biology of $\mathrm{Cx} 43$ in melanoma, and validate $\mathrm{Cx} 43$ as an important factor regulating growth, survival and metastasis formation.

\section{MATERIALS AND METHODS}

Cell culture. DFB, DFW, HF and FMS human melanoma cell lines were established and characterised at the Microbiology and Tumor Biology Center (MTC), Karolinska Institute, Sweden (SalazarOnfray et al, 2002). The lines were derived from metastatic lesions of patients treated at Radiumhemmet, Karolinska Hospital. DFW is a depigmented melanoma subline obtained from DFB by limiting dilution. Melanoma cells were grown at $37^{\circ} \mathrm{C}$ in an atmosphere with $5 \% \mathrm{CO}_{2}$ in RPMI 1640 culture medium (Invitrogen, Carlsbad, CA, USA), supplemented with $10 \%$ foetal bovine serum (FBS), penicillin $\left(100 \mathrm{Ul}^{-1}\right)$, streptomycin $\left(100 \mu \mathrm{g} \mathrm{ml}^{-1}\right)$ and $1 \mu \mathrm{M} \mathrm{L}$-glutamine. The pIRES-Cx43-transfected cells were grown in the same medium in the presence of geneticin G418 $\left(250 \mu \mathrm{g} \mathrm{ml}^{-1}\right.$; Invitrogen). Cells were incubated with $300 \mu \mathrm{M}$ of GJ-inhibitory Cx43-specific mimetic peptide 1848 (CNTQQPGCENVCY, extracellular loop 1; 95\% purity), Cx43-specific gap20 control peptide (EIKKFKYGIEEHC, cytoplasmic loop; 95\% purity) (Mendoza-Naranjo et al, 2011) or $5 \mu \mathrm{M}$ of the Cx43-specific peptide 5 (P5), which prevent hemichannel opening but do not disrupt GJ communication (VDCFLSRPTEKT, extracellular loop 2; 955 purity) (O'Carroll et al, 2008). Peptides were purchased from GenScript (Piscataway, NJ, USA).

Cell immune fluorescence staining and confocal microscopy. Melanoma cells were grown on poly-L-lysine-coated slides (Sigma-Aldrich, Steinheim, Germany). Cells were washed two times with PBS and fixed with $4 \%$ paraformaldehyde (PFA) for $30 \mathrm{~min}$. After gentle washing with PBS, the cells were incubated in ammonium chloride $(50 \mu \mathrm{M})$ for $10 \mathrm{~min}$, were permeabilised with
$0.5 \%$ Triton $\mathrm{X}-100$ for $10 \mathrm{~min}$, and blocked with $0.5 \%$ bovine serum albumin (BSA). Cells were then incubated with the antiCx43 polyclonal antibody (C6219; Sigma-Aldrich) overnight at $4{ }^{\circ} \mathrm{C}$. Samples were stained with a secondary donkey anti-rabbit FITC-conjugated Ab (Poly4064; BioLegend, San Diego, CA, USA) and $5 \mu \mathrm{g} \mathrm{ml}^{-1}$ Hoechst 33342 (Invitrogen) and mounted using DAKO fluorescence mounting medium. The samples were analysed using a Nikon Eclipse C2si confocal microscope (Plan Apo VC60X OIL DIC N2, NA: 1.4). Images were acquired using the NIS element AR V3.2 software (Nikon, Melville, NY, USA).

Flow cytometry. Flow cytometry experiments were performed as described previously (Tittarelli et al, 2014). Cells were fixed and permeabilised with Intracellular Fixation and Permeabilisation Buffer Set (BD Pharmingen, San Jose, CA, USA). Subsequently, melanoma cells were incubated with an $\mathrm{F}(\mathrm{ab}) 2$ rabbit polyclonal anti-Cx43 directed to the C-terminal domain (C6219; SigmaAldrich) followed by a secondary donkey anti-rabbit FITCconjugated Ab (Poly4064; BioLegend). Samples were acquired on a FACSCalibur (BD Biosciences, Franklin Lakes, NJ, USA) and analysed using the FCS Express 4 plus software (DeNovo, Glendale, CA, USA) or FlowJo (version 8.8.6; Tree Star, Ashland, OR, USA).

Cx43 stable transfection. FMS cells were transfected using FugeneHD (Roche Diagnostic, Indianapolis, IN, USA), according to the manufacturer's instructions, with a empty pIRES vector (Clontech Laboratories, Palo Alto, CA, USA) or containing the $\mathrm{CMV}$ promoter controlling the expression of the wild-type $\mathrm{Cx} 43$ cDNA, as described previously (Becker et al, 2001). Cells were selected in $250 \mathrm{\mu g} \mathrm{ml}^{-1}$ geneticin G418 (Promega, Madison, WI, USA) $48 \mathrm{~h}$ after transfection. Clonal cell populations were obtained by limiting dilution method.

Calcein-AM dye transfer assay. The calcein-AM dye transfer assay was performed according to a previously described method (Czyz et al, 2000). Briefly, donor melanoma cells were loaded with $1 \mu \mathrm{M}$ calcein-AM (C-1359; Sigma-Aldrich) and acceptor melanoma cells were loaded with Dil (15 $\mu \mathrm{g} \mathrm{ml}^{-1}$; D-282; Molecular Probes, Eugene, OR, USA) for $30 \mathrm{~min}$ at room temperature. After thoroughly washing with PBS, both cell types were cocultured at a $1: 1$ ratio (calcein ${ }^{+}$-donor cells : $\mathrm{Dil}^{+}$-acceptor cells) for $60 \mathrm{~min}$ at $37^{\circ} \mathrm{C}$. Calcein transfer from the donor to the acceptor cells was evaluated by flow cytometry, determining the percentage of calcein $^{+}$cells among the $\mathrm{Dil}^{+}$cells. Calcein transfer assays were carried out in the presence of the $\mathrm{Cx} 43$-specific mimetic peptide 1848, control peptide gap20 or P5.

CFSE cell proliferation assay. Melanoma cells were synchronised by serum deprivation for $48 \mathrm{~h}$. Thereafter, the cells were labelled with CFSE at a final concentration of $5 \mu \mathrm{M}\left(37^{\circ} \mathrm{C}\right.$ for $\left.10 \mathrm{~min}\right)$, and cultured in serum-supplemented medium for additional $24 \mathrm{~h}$. Flow cytometric analysis of cell proliferation by CFSE dilution was performed as described previously (Rödel et al, 2005).

$\left[{ }^{3} \mathbf{H}\right]$ thymidine incorporation assay. Melanoma cells were synchronised by serum deprivation for $48 \mathrm{~h}$. Thereafter, the cells were cultured in the presence of serum and proliferation was measured by $\left[{ }^{3} \mathrm{H}\right]$ thymidine uptake (Topcount NXT; Perkin-Elmer, Waltham, MA, USA) at $24 \mathrm{~h}$ according to standard methods. Proliferation was evaluated in cells untreated or pretreated for $4 \mathrm{~h}$ (before $\left[{ }^{3} \mathrm{H}\right]$ thymidine addition) and treated every $4 \mathrm{~h}$ with 1848 or gap20 peptides.

Western blot. Equal amounts of protein $(30 \mu \mathrm{g})$ extracted from FMS-EV - or FMS-Cx43-transfected cells were separated by $12 \%$ SDS-PAGE followed by electrotransfer to nitrocellulose membranes (Hybond; Amersham Biosciences, Piscataway, NJ, USA). Connexin 43 expression was examined as described (MendozaNaranjo et al, 2007), using an anti-human Cx43 polyclonal antibody (Sigma-Aldrich). Total lysates were probed with 
anti- $\beta$-actin antibody (Sigma-Aldrich) as a loading control. Signal was visualised using a chemiluminescence substrate system (Biological Industries, Amersham Biosciences).

Apoptotic cell analysis. FMS-EV- or Cx43-transfected cells were incubated or not with $200 \mathrm{ng} \mathrm{ml}^{-1}$ of tumour necrosis factor- $\alpha$ (TNF- $\alpha$ ) for $24 \mathrm{~h}$. Annexin-V and propidium iodide (PI) staining was used to analyse apoptosis according to the manufacturer's instructions (Apoalert; Clontech Laboratories Inc.).

Mice. Nonobese diabetic/SCID mice were obtained from the Jackson Laboratory (Bar Harbor, ME, USA) and kept in filtered cages under pathogen-free conditions in the high security animal facilities of the Institute of Biomedical Science, University of Chile. All experiments requiring animals were approved by the Faculty of Medicine Bioethical Committee and performed according to Home Office Animal Welfare Legislation.

Melanoma cell xenotransplantation and metastasis experiments. Eight-week-old NOD/SCID mice (three per group) were subcutaneously injected into the right flank with $5 \times 10^{5}$ FMS, DFB, FMS-EV or FMS-Cx43 cells. Tumour growth was monitored every 2-3 days by measuring the tumour volume with a calliper. Tumour volume was calculated according to the equation: (longer diameter $\times$ shorter diameter $)^{2} / 2$. For lung metastasis assay, 8week-old NOD/SCID mice (six per group) were injected with $2.5 \times 10^{5}$ FMS-EV cells, FMS-Cx43 cells or saline solution $(100 \mu \mathrm{l})$ intravenously into the tail vein. After 18 days, the mice were killed and autopsied to analyse melanoma lung metastasis.

Tumour immunohistochemical and immunofluorescence staining. Lungs from animals injected with FMS-EV and FMS-Cx43 cells were fixed with $2 \%$ PFA for $12 \mathrm{~h}$ at $4{ }^{\circ} \mathrm{C}$, dehydrated with $75 \%$ ethanol, rinsed in Xilol and then paraffin-embedded. Next, $3 \mu \mathrm{m}$ sections were obtained, which subsequently underwent treatment with $0.01 \mathrm{~mm}$ EDTA for antigen retrieval, followed by a $10 \mathrm{~min}$ treatment with $3 \%$ hydrogen peroxide to block endogenous peroxidase activity. The samples were thereafter washed two times with $0.05 \%$ PBS/Tween. Finally, the sections were incubated with $4 \%$ BSA/PBS for $30 \mathrm{~min}$ and then labelled with anti-cleaved caspase-3 (asp175) antibody (Cell Signalling Technology, Beverly, MA, USA; 1:50 dilution), or anti-Melan-A (Mart-1) mouse monoclonal antibody (Dako, Tokyo, Japan; $10 \mu \mathrm{g} \mathrm{ml}^{-1}$ ), for $1 \mathrm{~h}$ at room temperature. The samples were then washed two times with $0.05 \%$ Tween/PBS before incubation with the respective secondary peroxidase antibody (Vector Laboratories, Burlingame, CA, USA) for $30 \mathrm{~min}$. Samples were incubated with $\mathrm{ABC}$ solution (Vectastain ABC Kit; Vector Laboratories) for $20 \mathrm{~min}$ at $37^{\circ} \mathrm{C}$, and revealed with the chromogenic substrate $\mathrm{DAB}$ (Vector Laboratories). Human gonadal tissues were used as a positive control and lung tissues from non-injected animals were used as a negative control.

For immunostaining assay, an anti-Cx43 polyclonal antibody (Sigma-Aldrich) was used overnight at $4{ }^{\circ} \mathrm{C}$, followed by incubation with a secondary donkey anti-rabbit Alexa Fluor 488-conjugated antibody (Life Technologies, Carlsbad, CA, USA). Samples were additionally stained with $5 \mu \mathrm{g} \mathrm{ml}^{-1}$ Hoechst 33342 (Invitrogen) and visualised by confocal microscopy (LSM 510; 363 numerical aperture 1.4 oil immersion objective; Carl Zeiss, Jena, Germany).

Statistics. Statistical analyses were performed using the GraphPad Prism 3.0 program (GraphPad Software Inc., San Diego, CA, USA). Differences between experimental and control were tested by applying ANOVA test. Results are expressed as the mean \pm s.e.m. In all experiments a $P<0.05$ was considered statistically significant.

\section{RESULTS}

Cx43 expression correlates with GJIC in human melanoma cells. Connexin 43 expression was analysed in four different human metastatic melanoma cell lines, named FMS, HF, DFW and DFB. Total Cx43 expression was assessed by flow cytometry on permeabilised melanoma cells. As depicted in Figure 1A, DFW and HF cells showed higher total Cx43 levels compared with FMS and DFW cells. To examine the potential role of Cx43 expression in GJ formation between these cells, we analysed its cellular localisation by immunofluorescence and confocal microscopy. Weak positive Cx43 cytosolic and nuclear staining was observed in all melanoma cell lines analysed (Figure 1B). However, $\mathrm{Cx} 43$ clustering in cell-cell contact areas (white arrows) was only detected in HF cells, indicating the low frequency of occurrence of Cx43-GJ plaques in melanoma cells.

The presence of functional GJIC among melanoma cells was then monitored by calcein-AM transfer assays in the four cell lines (Figure 2A). Melanoma cells with the lowest levels of $\mathrm{Cx} 43$ expression (FMS) had the lowest incidence of dye coupling (FMS: $4.7 \pm 0.4 \%$ compared with DFW: $6.9 \pm 0.8 \%$; DFB: $8.3 \pm 1.1 \%$; HF: $8.6 \pm 1 \%$ ) (Figure $2 \mathrm{~A}$, lower panel). The transfer of calcein-AM was significantly reduced when the cells were cultured in the presence of an inhibitory Cx43-specific mimetic peptide (1848) compared with cells treated with the control gap20 peptide (Figure 2A, lower panel), indicating that $\mathrm{Cx} 43-\mathrm{GJ}$ channels are required for functional GJIC between these melanoma cells.

Additionally, CFSE dilution assays indicated that FMS melanoma cells with the lowest levels of both Cx43 expression and GJIC displayed the highest rate of in vitro cell proliferation, compared with DFW and DFB cells (Figure 2B).

We then assessed tumour growth rate in NOD/SCID mice xenotransplanted with FMS or DFB, the melanoma cell lines with the lowest and highest Cx43-mediated cell coupling and highest and lowest in vitro proliferation levels, respectively. In line with the in vitro observations, FMS tumours grew faster than DFB tumours in vivo (Figure $2 \mathrm{C}$ ).

Cx43 overexpression reduces proliferation rates and increases susceptibility to apoptosis in FMS melanoma cells. To address the direct effect of $\mathrm{Cx} 43$ in melanoma cell proliferation, $\mathrm{Cx} 43$ containing vectors or empty vectors (EV) were stably transfected in FMS cells. Connexin 43 overexpression was confirmed by western blotting and flow cytometric analysis of FMS cells (Figures $3 \mathrm{~A}$ and B). Additionally, we analysed $\mathrm{Cx} 43$ subcellular localisation by confocal microscopy. As depicted in Figure 3C, overexpression of $\mathrm{Cx} 43$ was associated with the occurrence of $\mathrm{Cx} 43-\mathrm{GJ}$ plaque structures at the cell-cell interface (white arrows), whereas FMS-EV cells showed weak and mainly nuclear Cx43 staining. In accordance with these results, FMS-Cx43 cells showed increased incidence of dye coupling compared with control FMS-EV cells $(21.5 \pm 2.6$ vs $6.7 \pm 1.8)$ (Figure 3D). Dye transfer was markedly reduced when FMS-Cx43 cells were cultured in the presence of peptide 1848, but not in cells treated with the control peptide gap20 or with a Cx43-hemichannel-specific inhibitory peptide (P5) (Figure 3D).

Connexin 43 overexpression induced a significant reduction in the proliferation rate of FMS cells (Figure 3E), which was completely reverted after incubation with the inhibitory $\mathrm{Cx} 43$ specific mimetic peptide 1848 (Figure 3E). These data demonstrate that $\mathrm{Cx} 43$ expression in melanoma cells regulates their proliferative potential, likely through a mechanism dependent on GJ-mediated intercellular communication.

It has been shown that $\mathrm{Cx} 43$ overexpression in prostate cancer cells increases their susceptibility to TNF- $\alpha$-induced apoptosis (Wang et al, 2007). To establish whether Cx43 expression is 


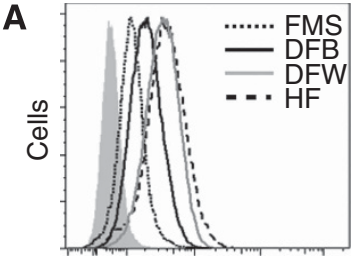

Cx43

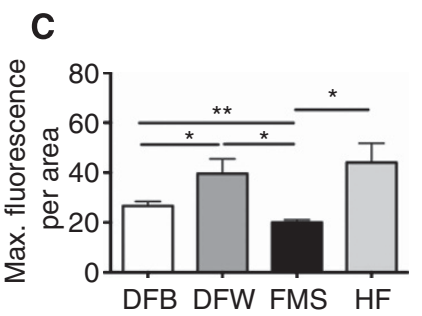

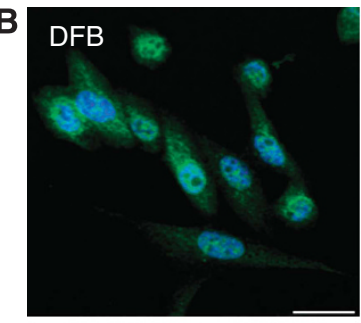
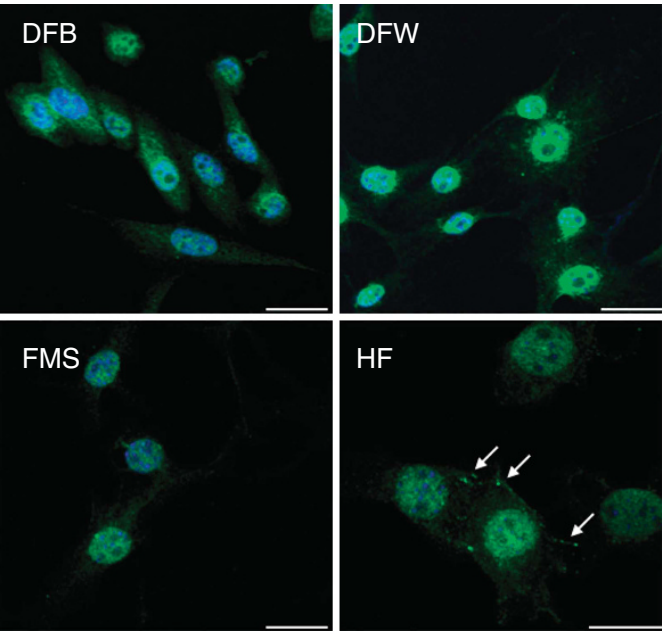

Figure 1. Connexin 43 expression in human melanoma cells. Total $\mathrm{C} \times 43$ expression pattern was evaluated by immunofluorescence staining and analysed by flow cytometry (A) or confocal microscopy (B and $\mathbf{C}$ ) in four different human melanoma cell lines (FMS, HF, DFW and DFB). (A) The histogram shows the relative expression of $\mathrm{Cx} 43$ in the four human melanoma cell lines. Filled grey histogram correspond to the isotype control staining. (B) Representative images of Cx43 (green) distribution. Blue: nucleus staining (Hoechst). The Cx43 accumulated in GJ plaques are indicated with white arrows. Scale bars, $5 \mu \mathrm{m}$. (C) Quantification of $\mathrm{C} x 43$ fluorescence signal intensities. ${ }^{\star} P<0.05 ;{ }^{\star \star} P<0.01$.

A
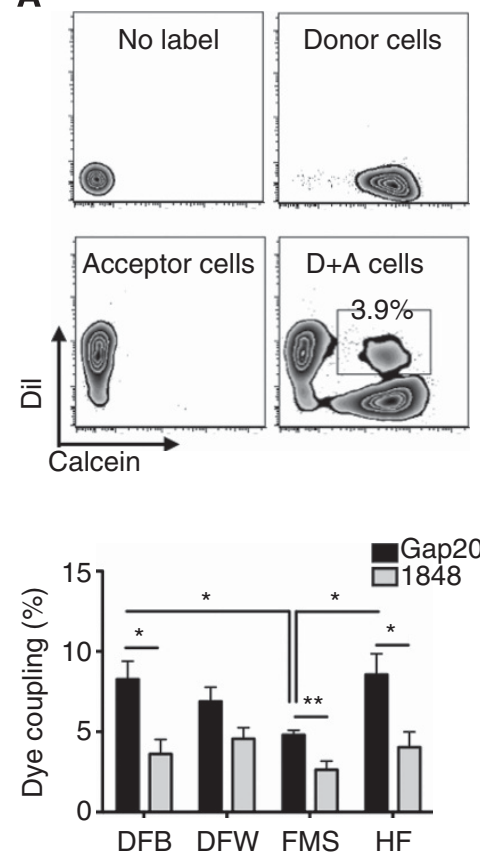

B
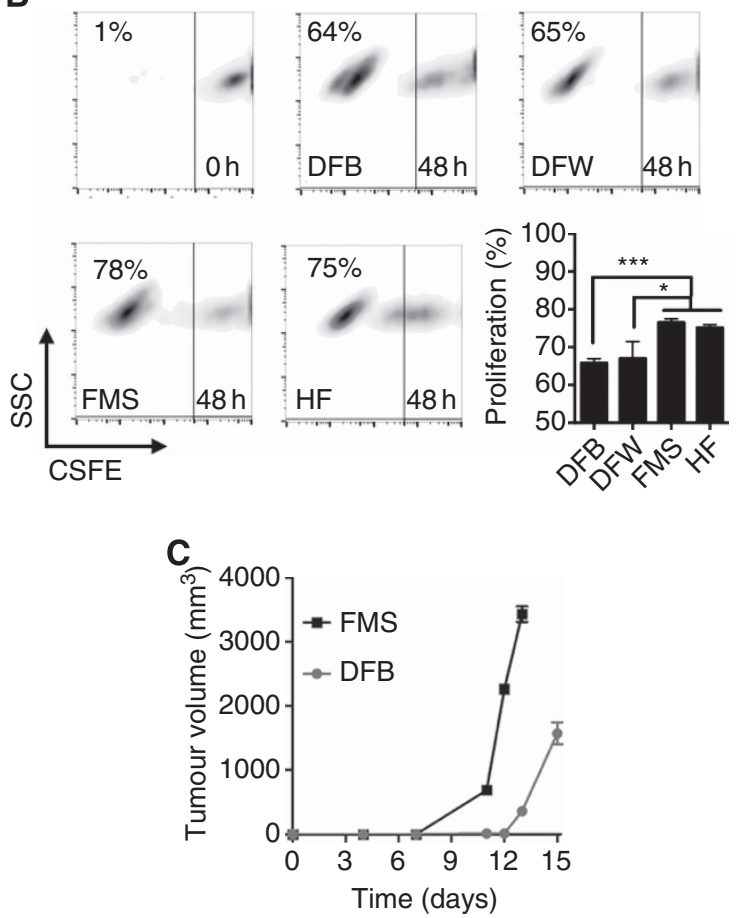

Figure 2. Connexin 43-mediated cell coupling and proliferation level in human melanoma cells. (A) Melanoma cells were preloaded with calceinAM (GJ-diffusible dye) or Dil-CM (non-GJ-diffusible dye) and cocultured for $60 \mathrm{~min}$ in a $1: 1 \mathrm{ratio}^{(c a l c e i n}{ }^{+} \mathrm{Dil}^{-}$donor cells: calcein $^{-}$Dil ${ }^{+}$acceptor cells) in the presence of control (gap20) or inhibitory (1848) Cx43-specific mimetic peptide. The calcein transfer from the $\mathrm{Dil}^{-}$to $\mathrm{Dil}^{+} \mathrm{cells}$ was assessed by flow cytometry. (A, lower panel) Bar graphs show the percentage of calcein ${ }^{+} \mathrm{Dil}^{+}$cells and correspond to results from three independent experiments. (B) Proliferation was determined by CFSE (carboxyfluorescein succinimidyl ester) dilution and flow cytometry in synchronised melanoma cell cultures. Percentages of proliferating cells are indicated in the representative densities plots and in the bar graphs $(n=3)$. (C) Nonobese diabetic (NOD)/LtSz-scid IL2Ry ${ }^{\text {null }}$ mice received a single subcutaneous injection of FMS or DFB ( 500000 cells), and the growth of primary tumours was monitored for 15 days $\left(n=3\right.$ mice per group). The growth curves are statistically different $(P<0.01)$. ${ }^{*} P<0.05$; ${ }^{\star *} P<0.01 ;{ }^{* \star \star} P<0.001$.

involved in the control of cell survival in human melanoma cells, we measured the percentage of apoptotic FMS-Cx43 and FMS-EV cells before and after TNF- $\alpha$ incubation. Both the basal percentage of early apoptotic cells (annexin- $\mathrm{V}^{+} \mathrm{PI}^{-}$) and total dying cells (annexin- $\mathrm{V}^{+}$) were higher in FMS-Cx43 compared with that in
FMS-EV cells $(5.9 \pm 1.7 \%$ compared with $3.2 \pm 0.4 \%$; $11.1 \pm 2.3 \%$ compared with $6.2 \pm 1.3 \%$; Figures $4 \mathrm{~A}-\mathrm{C}$ ). Tumour necrosis factor- $\alpha$ treatment did not increase the fraction of early apoptotic or total dying cells in FMS-EV (Figures 4A and B). However, the fraction of early apoptotic cells was increased in FMS-Cx43 treated 
A

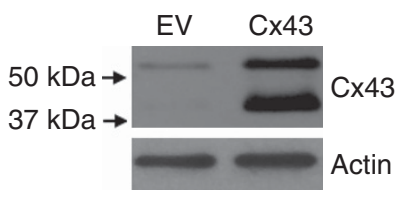

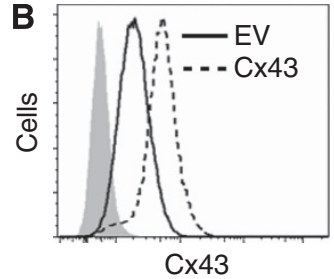

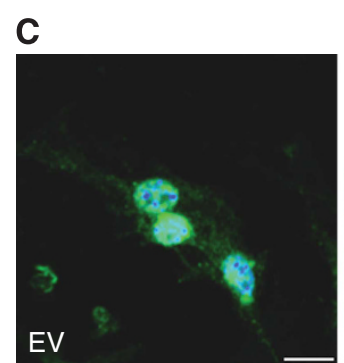

D
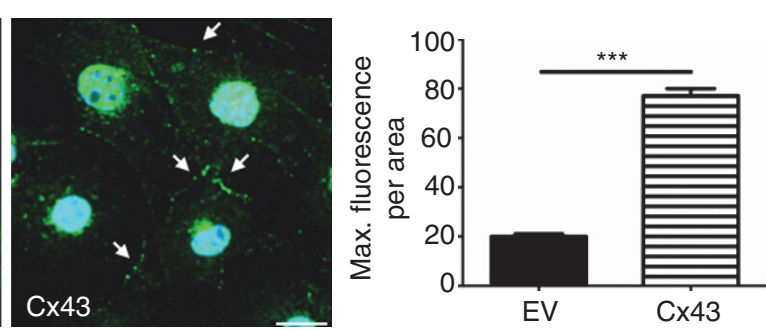
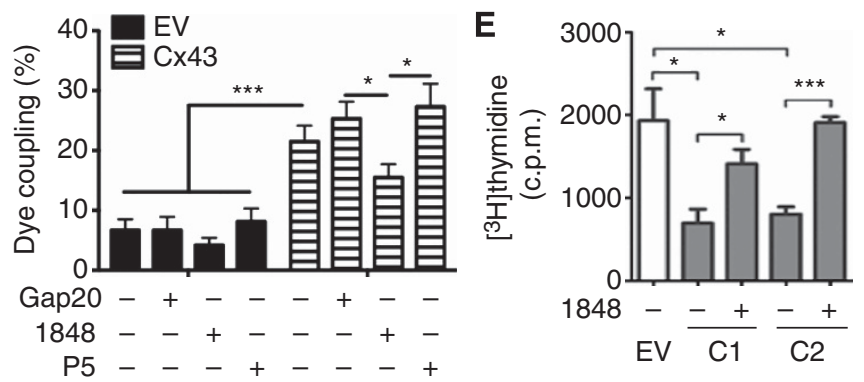

Figure 3. Connexin 43 overexpression increases GJ coupling and reduces melanoma cell proliferation. (A-C) Connexin 43 expression was measured in FMS cells stably transfected with $\mathrm{Cx} 43$ or in control cells (transfected with the control empty vector (EV)) by western blot (A), flow cytometry (B) or immunofluorescence microscopy (C). (A) $\beta$-Actin was used as a loading control. (B) Grey histogram corresponds to isotype control. (C, left) Cx43 (green)-positive GJ plaque structures are indicated with white arrows. Blue: nucleus staining (Hoechst). Scale bars, $5 \mu \mathrm{m}$. (C, right) Bar graphs show the quantification of the Cx43 fluorescence intensities. (D) FMS-EV or FMS-Cx43 melanoma cells were preloaded with calcein-AM or Dil-CM and cocultured for $60 \mathrm{~min}$ in a 1:1 ratio (calcein ${ }^{+}$Dil $^{-}$donor cells: calcein ${ }^{-}$Dil $^{+}$acceptor cells) in the presence of control (gap20) or inhibitory (1848) Cx43-specific mimetic peptides. Alternatively, cells were treated with a hemichannel-specific Cx43-mimetic inhibitory peptide (P5). Bar graphs show the percentage of calcein ${ }^{+} \mathrm{Dil}^{+}$cells $(n=3)$. (E) The incorporation of $\left[{ }^{3} \mathrm{H}\right]$ thymidine assays were carried out to determine the proliferative rate of two FMS-Cx43 clones (C1 and C2) or the control FMS-EV cells. Cells were cultured in the presence of control gap20 $(-)$ or inhibitory 1848 peptides $(+)(n=3) .{ }^{\star} P<0.05 ;{ }^{\star \star \star} P<0.001$.

with TNF- $\alpha$ compared with untreated cells $(10.2 \pm 1.2 \%$ vs $5.9 \pm 1.7 \%$; Figures $4 \mathrm{~A}$ and $\mathrm{B})$. Taken together, these results show that in addition to a reduction in cell proliferation, $\mathrm{Cx} 43$ expression increases basal and TNF- $\alpha$-induced apoptosis in melanoma cells.

Cx43 overexpression reduces melanoma tumour growth and lung metastasis in xenotransplanted mice. To investigate the role of Cx43 expression in melanoma tumour growth and lung metastasis formation in vivo, FMS-Cx43 and FMS-EV control cells were injected subcutaneously or intravenously, respectively, in NOD/SCID mice. In line with our in vitro observations, we found that $\mathrm{Cx} 43$ overexpression significantly deaccelerated tumour growth in xenotransplanted mice (Figure 5A). In contrast, tumours arising from control melanoma FMS-EV cells grew significantly faster, and mice had to be killed 16 days after inoculation. Similar data were observed in terms of metastatic spread. Whereas FMSEV melanoma cells gave rise to multiple metastatic pulmonary foci, the highly metastatic potential of the FMS cells was strongly inhibited by overexpression of $\mathrm{Cx} 43$ (Figure 5B). These data illustrate a tumour-intrinsic role of $\mathrm{Cx} 43$ in the regulation of melanoma metastatic spread in the absence of an immune response. Moreover, immunohistochemical analysis showed that both the multiple and bigger tumours found in animals inoculated with FMS-EV cells and the less frequent and smaller tumours produced by the FMS-Cx43 injected cells both expressed the melanoma marker Mart-1 (Figure 5C), ruling out a putative role of $\mathrm{Cx} 43$ in the dedifferentiation of melanoma cells in vivo. Interestingly, immunostaining showed that FMS-Cx43 metastatic tumours expressed higher levels of both Cx43-based GJs and active caspase3 in vivo, compared with FMS-EV tumours (Figures 5D and E). Altogether, these results suggest that $\mathrm{Cx} 43$ expression in melanoma cells decreases their tumorigenic and metastatic potential influencing both proliferation and survival rates, likely through a GJICdependent mechanism.

\section{DISCUSSION}

The current study provides direct evidence of the impact of $\mathrm{Cx} 43$ expression in human melanoma growth and metastatic behaviour in vitro and in vivo, at least in the last steps of metastasis formation, that is, extravasation, survival and growth in a distant organ. The tumour suppressor properties of Cx43 may be complex, cancer type-specific and may involve both channel (GJ and hemichannels)-dependent and -independent mechanisms. A recent study in B16-BL6 cells, a mouse melanoma cell line with low levels of Cx43 expression, reported a decreased proportion of cells in the $\mathrm{S}$ phase of the cell cycle after Cx43 overexpression (Ableser et al, 2014). Inhibition in cell proliferation was further associated with an increase in homocellular GJIC between melanoma cells when 
A

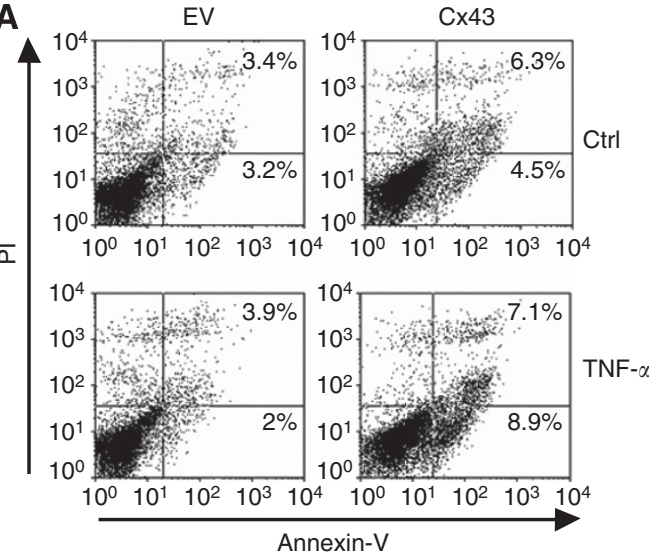

B

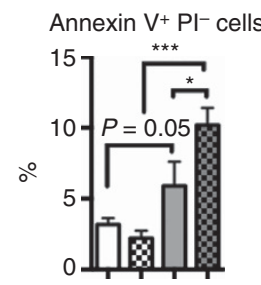

Annexin $\mathrm{V}^{+} \mathrm{PI}^{-}$cells

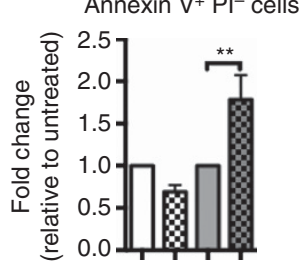

Annexin $\mathrm{V}^{+}$cells

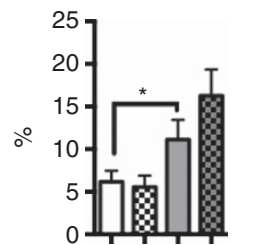

Annexin $\mathrm{V}^{+} \mathrm{Pl}^{-}$cells

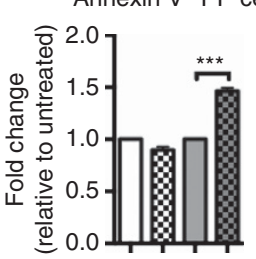

$\square$ EV-Ctrl

EV-TNF- $\alpha$

$\square \mathrm{Cx} 43-\mathrm{Ctrl}$

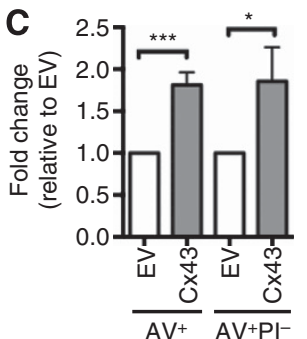

Figure 4. Connexin 43 overexpression increases basal and tumour necrosis factor- $\alpha$ (TNF- $\alpha$ )-induced apoptosis in melanoma cells. Representative dot plots (A) and graphs show the distribution of propidium iodide (PI) and annexin-V (AV) staining in FMS-EV or FMS-Cx43 cells, untreated or treated for $24 \mathrm{~h}$ with $200 \mathrm{ng} \mathrm{ml}^{-1}$ of TNF- $\alpha$. (B) Bar graphs show the early apoptotic $\left(\mathrm{AV}^{+} \mathrm{Pl}^{-}\right)$or total dying $\left(\mathrm{AV}^{+}\right)$cells represented as the percentage of positive cells (upper panels) or as fold change relative to untreated cells (lower panels). (C) The basal level of early apoptotic $\left(\mathrm{AV}^{+} \mathrm{PI}^{-}\right)$or total dying $\left(\mathrm{AV}^{+}\right)$FMS-Cx43 cells are shown as fold change relative to FMS-EV cells $(n=3) .{ }^{\star} P<0.05 ;{ }^{\star \star} P<0.01 ;{ }^{\star \star \star} P<0.001$.

cocultured in the presence of keratinocytes, although restoration of heterocellular GJIC was not observed (Ableser et al, 2014). These data, along with our current findings, suggest that, through a yet unknown mechanism, Cx43-mediated intercellular communication in melanoma control cell growth and proliferation in both human and murine models.

It has been shown that $\mathrm{Cx} 43$ reduces proliferation in glioblastomas, osteosarcoma and ovarian carcinoma by inhibiting cell cycle progression through increased p27 expression and inhibition of the S-phase kinase-associated protein Skp2 (Huang et al, 1998; Zhang et al, 2003). Ectopic expression of $\mathrm{Cx} 43$ in breast tumour cells induces tumour-suppressive properties through the downregulation of fibroblast growth factor receptor 3 (Qin et al, 2002). Moreover, $\mathrm{Cx} 43$ can interact with over 30 distinct proteins, including proteins with a tumour suppressor role such as caveolin 1 (Langlois et al, 2010) and CCN3 (Gellhaust et al, 2004; Sin et al, 2009).

Key molecules associated with cell proliferation/survival and which are permeable to $\mathrm{Cx} 43$ channels include $\mathrm{NAD}^{+}$, ATP, $\mathrm{Ca}^{2+}, \mathrm{IP}_{3}$, glutathione and prostaglandin E2 (Decrock et al, 2009). Accordingly, it has been shown that inhibition of $\mathrm{Cx} 43$ channels by 18 - $\beta$-glycyrrhetinic acid induces cell proliferation by modulating intracellular ATP and $\mathrm{Ca}^{2+}$ levels (Song et al, 2010). Intracellular $\mathrm{Ca}^{2+}$ signalling and the generation of intercellular $\mathrm{Ca}^{2+}$ waves have been involved in key cancer-related process including escape from apoptosis, perpetuation of growth and metastasis (Monteith et al, 2012). Particularly, higher intracellular $\mathrm{Ca}^{2+}$ concentrations favour cell proliferation by promoting remodelling of the actin cytoskeleton (Monteith et al, 2012).

Our results also showed that expression of $\mathrm{Cx} 43$ in melanoma cells increases both basal and TNF- $\alpha$-induced apoptosis of FMS melanoma cells. Interestingly, FMS-Cx43 metastatic lung tumours displayed higher $\mathrm{Cx} 43-\mathrm{GJ}$ plaques accompanied by active caspase-3. These data are consistent with previous studies showing that restoration of $\mathrm{Cx} 43$ expression in tumour cells correlates with the inhibition of tumour growth and expression of genes involved in the regulation of the cell cycle and apoptosis including Bcl-2 and caspase-3/7 (Hattori et al, 2007). Additional studies have shown that $\mathrm{Cx} 43$ overexpression stimulates apoptotic cell death via GJmediated transfer of proapoptotic signals such as $\mathrm{Ca}^{2+}$ and $\mathrm{IP}_{3}$ between cells (Decrock et al, 2009; Kameritsch et al, 2013; Carette et al, 2014). Furthermore, the absence of $\mathrm{Cx} 43$ and GJIC correlates with cancer stem cell features and expression of epithelial-tomesenchymal transition markers in pancreatic cancer cells (Forster et al, 2014), both associated with a higher basal viability, resistance to gemcitabine and enhanced clonogenic potential. Restoration of Cx43 expression and GJIC in melanoma cells could have an effect on proliferation, metastasis and induction of apoptosis through inhibition of its cancer stem cell characteristics (Trosko, 2003).

Although over 21 different isoforms of Cxs have been characterised in humans, only $\mathrm{Cx} 26$ and $\mathrm{Cx} 43$ are expressed in melanocytes (Hsu et al, 2000; Ito et al, 2000). During melanoma transformation and progression, the expression of Cxs is downregulated, thus promoting loss of communication with cells of the local microenvironment (Hsu et al, 2000; Masuda et al, 2001). Our results along with recent evidences (Zucker et al, 2013; Ableser et al, 2014) suggest that $\mathrm{Cx} 43$, and not $\mathrm{Cx} 26$, can act as a tumour suppressor during melanoma tumorigenesis. Following ectopic expression of GFP-tagged Cx26 and Cx43 in the Cx-deficient B16BL6 mouse melanoma cell line, expression of Cx43, but not Cx26, significantly reduced cellular proliferation and anchorageindependent growth in these cells (Ableser et al, 2014).

The role of Cxs in invasion and metastasis is controversial, and whereas several reports indicate that Cxs may reduce tumour 
A

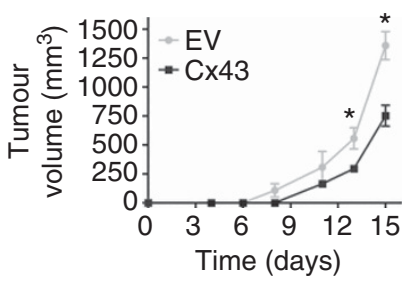

B

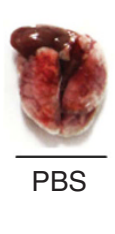

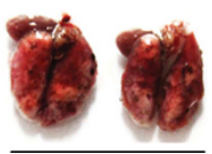

EV
Mart-1

C

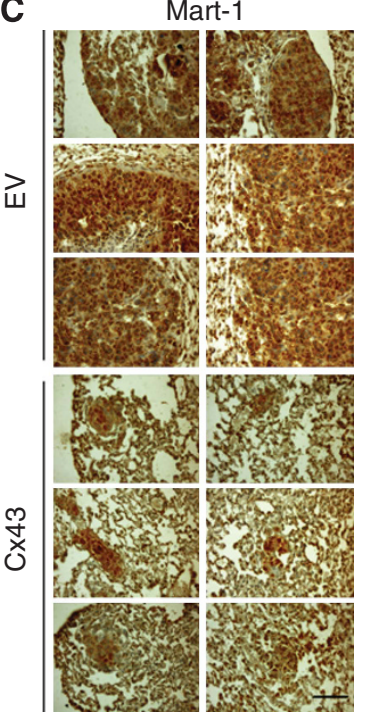

D
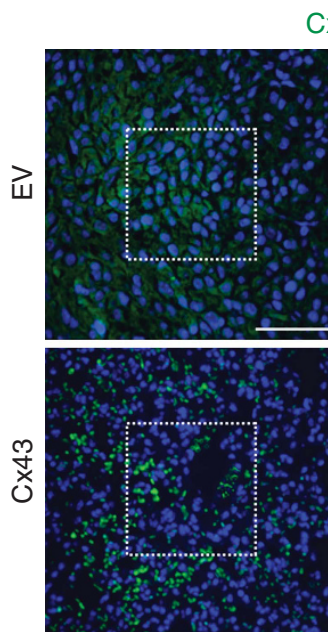

Cx43
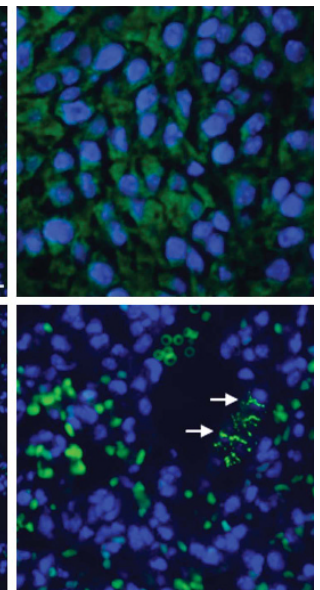
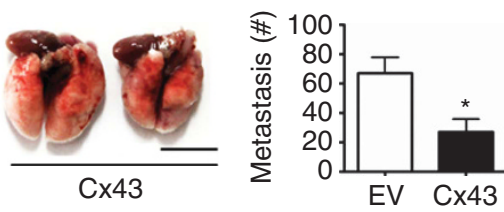

E
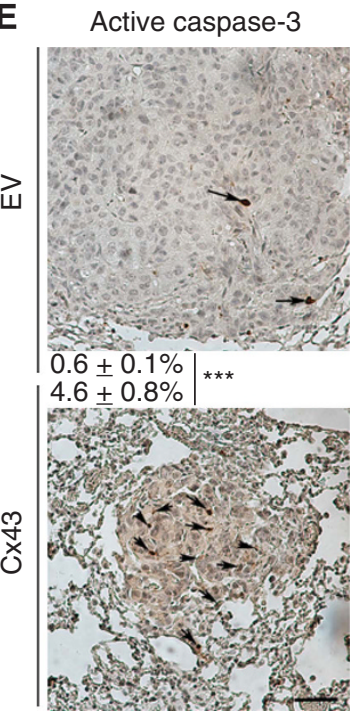

Figure 5. Connexin 43 overexpression reduces melanoma tumour growth and prevents metastasis in a xenotransplantation model. (A) Nonobese diabetic NOD/LtSz-scid IL2R $\gamma^{\text {null }}$ (NOD/SCID) mice received a single subcutaneous injection of FMS-EV or FMS-Cx43 (500 000 cells), and the growth of primary tumours was monitored for 15 days ( $n=3$ mice per group). (B) Nonobese diabetic/SCID mice received a single intravenous injection of FMS-EV, FMS-Cx43 (250000 cells) or PBS ( $n=6$ mice per group). The mice were terminated on day 18 after inoculation and the lungs were examined. The graph bar shows the number of metastasis counted in the lungs of six mice per group. Scale bar, $1 \mathrm{~cm}$. (C) Immunohistochemical staining of Mart-1 in melanoma lung metastasis biopsies of NOD/SCID mice injected with FMS-EV or FMS-Cx43 cells (overview of six mice per group). Scale bar, $25 \mu \mathrm{m}$. (D) Immunofluorescence analysis showed in vivo Cx43 expression (green) and Cx43-based GJ formation (white arrows) on melanoma lung metastasis biopsies of NOD/SCID mice injected with FMS-EV or FMS-Cx43 cells. Blue: nucleus staining (Hoechst). Enlarged images $(3 \times)$ marked by the white boxes are shown on the right. Scale bar, $30 \mu \mathrm{M}$. (E) Immunohistochemical staining of active caspase-3 (black arrows) in melanoma lung metastasis biopsies of NOD/SCID mice injected with FMS-EV or FMS-Cx43 cells (overview of six mice per group). Below and upper each photograph showed the number of active capsase-3 positive cells per $14 \mu \mathrm{m}^{2}$. Scale bar, $60 \mu \mathrm{m}$. ${ }^{\star} P<0.05 ;{ }^{\star \star \star} P<0.001$.

metastasis (Li et al, 2008; Sato et al, 2008; Bodenstine et al, 2010; Plante et al, 2011; Wang et al, 2013), other studies argue the opposite effect (Naus and Laird, 2010; Stoletov et al, 2013). Li et al (2008) observed that expressing $\mathrm{Cx} 43$ in breast cancer cells decreases their metastatic potential through a mechanism independent of GJIC but, rather, related to N-cadherin expression and apoptosis. N-cadherin expression is involved in epithelial-tomesenchymal transition in cancer cells by impairing cell polarity and cell-cell adhesion, and increasing a more migratory and invasive phenotype (Wheelock et al, 2008). However, our data point to a role for $\mathrm{Cx} 43$ expression regulating the last steps of the metastatic process, when tumour cells have to colonise distant organs such as the lung, and proliferate and survive in this new environment, which requires the reversion of EMT. Furthermore, recent data strongly suggest that $\mathrm{Cx} 43$ acts as a tumour suppressor protein, which may predict clinical outcomes in chemotherapytreated patients of different kind of cancers (Sirnes et al, 2012; Du et al, 2013; Wang et al, 2013). Moreover, we recently showed that $\mathrm{Cx} 43$ accumulates at the interface between natural killer (NK) cells and melanoma cells, facilitating the NK cell cytotoxic activity against melanoma (Tittarelli et al, 2014), suggesting a putative impact of tumour-Cx43 expression in immunotherapy outcomes from melanoma patients.
In summary, our findings propose an important role for $\mathrm{Cx} 43$ controlling melanoma growth and metastasis, likely through a mechanism dependent of GJ communication and induction of apoptosis. Therefore, it is tempting to speculate that the use of drugs that selectively enhance Cx43 expression on tumours and/or melanoma cells (Yi et al, 2006; Conklin et al, 2007) could enhance the efficacy of cancer therapies.

\section{ACKNOWLEDGEMENTS}

We thank Professor David Becker (Lee Kong Chian School of Medicine, Nanyang Technological University) for the kind gift of control and Cx43-containing pIRES plasmids.

\section{REFERENCES}

Ableser MJ, Penuela S, Lee J, Shao Q, Laird DW (2014) Connexin43 reduces melanoma growth within a keratinocyte microenvironment and during tumorigenesis in vivo. J Biol Chem 289: 1592-1603.

Becker D, Ciantar D, Catsicas M, Pearson R, Mobbs P (2001) Use of pIRES vectors to express EGFP and connexin constructs in studies of the role of 
gap junctional communication in the early development of the chick retina and brain. Cell Commun Adhes 8: 355-359.

Bodenstine TM, Vaidya KS, Ismail A, Beck BH, Cook LM, Diers AR, Landar A, Welch DR (2010) Homotypic gap junctional communication associated with metastasis suppression increases with PKA activity and is unaffected by PI3K inhibition. Cancer Res 70: 10002-10007.

Carette D, Gilleron J, Chevallier D, Segretain D, Pointis G (2014) Connexin a check-point component of cell apoptosis in normal and physiological conditions. Biochimie 101: 1-9.

Conklin CMJ, Bechberger JF, MacFabe D, Guthrie N, Kurowska E, Naus CC (2007) Genistein and quercetin increase connexin 43 and suppress growth of breast cancer cells. Carcinogenesis 28: 93-100.

Czyz J, Irmer U, Schulz G, Mindermann A, Hülser DF (2000) Gap-junctional coupling measured by flow cytometry. Exp Cell Res 255: 40-46.

Decrock E, Vinken M, De Vuyst E, Krysko DV, D'Herde K, Vanhaecke T, Vandenabeele P, Rogiers V, Leybaert L (2009) Connexin-related signaling in cell death: to live or let die? Cell Death Differ 16: 524-536.

Du G, Yang Y, Zhang Y, Sun T, Liu W, Wang Y, Li J, Zhang H (2013) Thrombocytosis and immunohistochemical expression of connexin 43 at diagnosis predict survival in advanced non-small-cell lung cancer treated with cisplatin-based chemotherapy. Cancer Chemother Pharmacol 71: 893-904.

Forster T, Rausch V, Zhang Y, Isayev O, Heilmann K, Schoensiegel F, Liu L, Nessling M, Richter K, Labsch S, Nwaeburu CC, Mattern J, Gladkich J, Giese N, Werner J, Schemmer P, Gross W, Gebhard MM, Gerhauser C, Schaefer M, Herr I (2014) Sulforaphane counteracts aggressiveness of pancreatic cancer driven by dysregulated Cx43-mediated gap junctional intercellular communication. Oncotarget 5: 1621-1634.

Fukushima M, Hattori Y, Yoshizawa T, Maitani Y (2007) Combination of non-viral connexin 43 therapy and docetaxel inhibits the growth of human prostate cancer in mice. Int J Oncol 30: 225-231.

Gellhaust A, Dong X, Propson S, Maass K, Klein-Hitpass L, Kibschull M, Traub O, Willecke K, Perbal B, Lye SJ, Winterhager E (2004) Connexin43 interacts with NOV. A possible mechanism for negative regulation of cell growth in choriocarcinoma cells. J Biol Chem 279: 36931-36942.

Haass N, Smalley K, Herlyn M (2004) The role of altered cell-cell communication in melanoma progression. J Mol Histol 35: 309-318.

Harris AL (2007) Connexin channel permeability to cytoplasmic molecules. Prog Biophys Mol Biol 94: 120-143.

Hattori Y, Fukushima M, Maitani Y (2007) Non-viral delivery of the connexin 43 gene with histone deacetylase inhibitor to human nasopharyngeal tumour cells enhances gene expression and inhibits in vivo tumour growth. Int J Oncol 30: 1427-1439.

Hervé JC, Derangeon M (2013) Gap-junction-mediated cell-to-cell communication. Cell Tissue Res 352: 21-31.

Hsu M, Andl T, Li G, Meinkoth JL, Herlyn M (2000) Cadherin repertoire determines partner-specific gap junctional communication during melanoma progression. J Cell Sci 113: 1535-1542.

Huang RP, Fan Y, Hossain MZ, Peng A, Zeng ZL, Boynton AL (1998) Reversion of the neoplastic phenotype of human glioblastoma cells by connexin 43 (cx43). Cancer Res 58: 5089-5096.

Huang R, Hossain MZ, Sehgal A, Boynton AL (1999) Reduced connexin 43 expression in high-grade human brain glioma cells. J Surg Oncol 70: 21-24.

Huang R, Lin Y, Wang CC, Gano J, Lin B, Shi Q, Boynton AL, Burke J, Huang RP (2002) Connexin 43 suppresses human glioblastoma cell growth by down-regulation of monocyte chemotactic protein 1 , as discovered using protein array technology. Cancer Res 62: 2806-2812.

Ito A, Katoh F, Kataoka TR, Okada M, Tsubota N, Asada H, Yoshikawa K, Maeda S, Kitamura Y, Yamasaki H, Nojima H (2000) A role for heterologous gap junctions between melanoma and endothelial cells in metastasis. J Clin Invest 105: 1189-1197.

Kameritsch P, Khandoga N, Pohl U, Pogoda K (2013) Gap junctional communication promotes apoptosis in a connexin-type-dependent manner. Cell Death Differ (2013) 4: e584.

Koulakoff A, Mei X, Orellana JA, Sáez JC, Giaume C (2012) Glial connexin expression and function in the context of Alzheimer's disease. Biochim Biophys Acta 1818: 2048-2057.

Krutovskikh V, Piccoli C, Yamasaki H (2002) Gap junction intercellular communication propagates cell death in cancerous cells. Oncogene 21: 1989-1999.

Laird DW (2010) The gap junction proteome and its relationship to disease. Trends Cell Biol 20: 92-101.
Langlois S, Cowan KN, Shao Q, Cowan BJ, Laird DW (2010) The tumoursuppressive function of Connexin 43 in keratinocytes is mediated in part via interaction with caveolin-1. Cancer Res 70: 4222-4232.

Li Z, Zhou Z, Welch DR, Donahue HJ (2008) Expressing connexin 43 in breast cancer cells reduces their metastasis to lungs. Clin Exp Metast 25: 893-901.

Masuda M, Usami S, Yamazaki K, Takumi Y, Shinkawa H, Kurashima K, Kunihiro T, Kanzaki J (2001) Connexin 26 distribution in gap junctions between melanocytes in the human vestibular dark cell area. Anat Rec $\mathbf{2 6 2}$ 137-146.

Mendoza-Naranjo A, Saéz PJ, Johansson CC, Ramírez M, Mandakovic D, Pereda C, López MN, Kiessling R, Sáez JC, Salazar-Onfray F (2007) Functional gap junctions facilitate melanoma antigen transfer and cross-presentation between human dendritic cells. J Immunol 178: 6949-6957.

Mendoza-Naranjo A, Bouma G, Pereda C, Ramírez M, Webb KF, Tittarelli A, López MN, Kalergis AM, Thrasher AJ, Becker DL, Salazar-Onfray F (2011) Functional gap junctions accumulate at the immunological synapse and regulate calcium signaling in T cells. J Immunol 187: 3121-3132.

Meşe G, Richard G, White T (2007) Gap junction: basic structure and function. J Invest Dermatol 127: 2516-2524.

Monteith GR, Davis FM, Roberts-Thomson SJ (2012) Calcium channels and pumps in cancer: changes and consequences. J Biol Chem 287: 31666-31673.

Naus CC, Laird DW (2010) Implications and challenges of connexin connections to cancer. Nat Rev Cancer 10: 435-441.

Neijssen J, Pang B, Neefjes J (2007) Gap junction-mediated intercellular communication in the immune system. Prog Biophys Mol Biol 94: $207-218$.

O'Carroll SJ, Alkadhi M, Nicholson LFB, Green CR (2008) Connexin43 mimetic peptides reduce swelling, astrogliosis, and neuronal cell death after spinal cord injury. Cell Commun Adhes 15: 27-42.

Pfenniger A, Wohlwend A, Kwak BR (2011) Mutations in connexin genes and disease. Eur J Clin Invest 41: 103-116.

Plante I, Stewart MKG, Barr K, Allan A, Laird DW (2011) Cx43 suppresses mammary tumour metastasis to the lung in a $\mathrm{Cx} 43$ mutant mouse model of human disease. Oncogene 30: 1681-1692.

Qin H, Shao Q, Curtis H, Galipeau J, Belliveau DJ, Wang T, Alaoui-Jamali MA, Laird DW (2002) Retroviral delivery of connexin genes to human breast tumour cells inhibits in vivo tumour growth by a mechanism that is independent of significant gap junctional intercellular communication. J Biol Chem 277: 29132-29138.

Rödel F, Franz S, Sheriff A, Gaipl U, Heyder P, Hildebrandt G, Schultze-Mosgau S, Voll RE, Herrmann M (2005) The CFSE distribution assay is a powerful technique for the analysis of radiation-induced cell death and survival on a single-cell level. Strahlenther Onkol 181: $456-462$.

Salazar-Onfray F, López M, Lundqvist A, Aguirre A, Escobar A, Serrano A, Korenblit C, Petersson M, Chhajlani V, Larsson O, Kiessling R (2002) Tissue distribution and differential expression of melanocortin 1 receptor, a malignant melanoma marker. Br J Cancer 87: 414-422.

Sato H, Hagiwara H, Senba H, Fukumoto K, Nagashima Y, Yamasaki H, Ueno $\mathrm{K}$, Yano T (2008) The inhibitory effect of connexin 32 gene on metastasis in renal cell carcinoma. Mol Carcinog 47: 403-409.

Sin WC, Tse M, Planque N, Perbal B, Lampe PD, Naus CC (2009) Matricellular proteon $\mathrm{CCN} 3(\mathrm{NOV})$ regulates actin cytoskeleton reorganization. J Biol Chem 284: 29935-29944.

Sirnes S, Bruun J, Kolberg M, Kjenseth A, Lind GE, Svindland A, Brech A, Nesbakken A, Lothe RA, Leithe E, Rivedal E (2012) Connexin43 acts as a colorectal cancer tumour suppressor and predicts disease outcome. Int J Cancer 131: 570-581.

Song D, Liu X, Liu R, Yang L, Zuo J, Liu W (2010) Connexin 43 hemichannel regulates $\mathrm{H} 9 \mathrm{c} 2$ cell proliferation by modulating intracellular ATP and $\left[\mathrm{Ca}^{2+}\right]$. Acta Biochim Biophys Sin (Shanghai) 42: 472-482.

Stoletov K, Strnadel J, Zardouzian E, Momiyama M, Park FD, Kelber JA, Pizzo DP, Hoffman R, VandenBerg SR, Klemke RL (2013) Role of connexins in metastatic breast cancer and melanoma brain colonization. J Cell Sci 126: 904-913.

Su YA, Bittner ML, Chen Y, Tao L, Jiang Y, Zhang Y, Stephan DA, Trent JM (2000) Identification of tumour-suppressor genes using human melanoma cell lines UACC903, UACC903 $(+6)$, and SRS3 by comparison of expression profiles. Mol Carcinogen 28: 119-127. 
Tittarelli A, Mendoza-Naranjo A, Farías M, Guerrero I, Ihara F, Wennerberg E, Riquelme S, Gleisner A, Kalergis A, Lundqvist A, López MN, Chambers BJ, Salazar-Onfray F (2014) Gap junction intercellular communications regulate NK cell activation and modulate NK cytotoxic capacity. J Immunol 192: 1313-1319.

Trosko JE (2003) The role of stem cells and gap junctional intercellular communication in carcinogenesis. J Biochem Mol Biol 36: 43-48.

Wang M, Berthoud V, Beyer E (2007) Connexin 43 increases the sensitivity of prostate cancer cells to TNF $\alpha$-induced apoptosis. J Cell Sci 120: 320-329.

Wang ZS, Wu LQ, Yi X, Geng C, Li YJ, Yao RY (2013) Connexin-43 can delay early recurrence and metastasis in patients with hepatitis B-related hepatocellular carcinoma and low serum alpha-fetoprotein after radical hepatectomy. BMC Cancer 13: 306.

Wheelock MJ, Shintani Y, Maeda M, Fukumoto Y, Johnson KR (2008) Cadherin switching. J Cell Sci 121: 727-735.
Yi ZC, Liu YZ, Li HX, Yin Y, Zhuang FY, Fan YB, Wang Z (2006) Tellimagrandin I enhances gap junctional communication and attenuates the tumour phenotype of human cervical carcinoma HeLa cells in vitro. Cancer Lett 242: 77-87.

Zhang Y, Kaneda M, Morita I (2003) The gap junction-independent tumour-suppressing effect of connexin 43. J Biol Chem 278: 44852-44856.

Zucker SN, Bancroft TA, Place DE, Des Soye B, Bagati A, Berezney R (2013) A dominant negative Cx43 mutant differentially affects tumorigenic and invasive properties in human metastatic melanoma cells. J Cell Physiol 228: 853-859.

This work is published under the standard license to publish agreement. After 12 months the work will become freely available and the license terms will switch to a Creative Commons AttributionNonCommercial-Share Alike 4.0 Unported License 